\title{
Short Arabic Plays: An Anthology
}

Salma Khadra Jayyusi, ed.

Northampton, MA: Interlink Books, 2003. 466 pages

Like most of the other anthologies edited by Salma Khadra Jayyusi, Short Arabic Plays is a collection of translated Arabic literary works focused around one particular genre. This anthology, part of Jayyusi's Project for the Translation of Arabic (PROTA), will bring attention to a dynamic, but understudied, genre of Arabic literature. This diverse collection consists of 20 short plays by 15 playwrights, demonstrating the breadth of the genre and its interest not only to scholars and specialists, but also to those concerned with literature more generally.

One problem with this particular anthology, however, is that Jayyusi's seven-page editor's introduction barely manages to explain the impetus behind the project, make her acknowledgments and outline the major themes in short plays in general - let alone contextualize the plays included in this volume. Although it includes short biographies of the editor, contributors, and translators (after a brief glossary of Arabic words), there are no introductions to the individual works or even such bibliographic indications as their original titles and dates of publication. In contrast, other anthologies by Jayyusi - for example, Modern Arabic Poetry: An Anthology (Columbia University Press: 1987) and Anthology of Modern Palestinian Literature (Columbia University Press: 1992) - are accompanied by useful and lengthy introductions written by Jayyusi herself, as well as brief introductions to each individual contribution.

Likewise, the anthology most closely related to this one, Modern Arabic Drama: An Anthology, coedited with Roger Allen (Indiana 
University Press: 1995) contains a preface by the editors, an introduction by M. M. Badawi, and short introductions to each play. In her introduction, Jayyusi notes that Short Arabic Plays complements Modern Arabic Drama. Indeed, it is almost needed as a companion volume for the non-specialist to gain some understanding of the different playwrights, literary periods, styles, and so on. This missing information is particularly problematic in the case of Short Arabic Plays, because it treats such a little-known genre. Moreover, as a reference work largely intended for readers of English who are likely not well-versed in Arabic literature, more detailed information and context about the literary works is important and would have been extremely helpful.

Though in many ways this collection is broad, in others it is somewhat limited. The playwrights are Egyptian, Emirati, Lebanese, Libyan, Iraqi, Palestinian, Syrian, and a Jordanian of Syrian origin. Most of them are wellknown literary figures, with one exception - whose contribution is wellworth being included - is the only female playwright: Samia Qazmouz Bakri. Bakri's monodrama "The Alley" is a reminiscence about life in Akka before and after the Israeli occupation. The North African countries of Algeria, Morocco, and Tunisia have no representation, nor do the countries of the Gulf, other than "The Return of Hulegu," penned by the reigning shaykh of the Emirate of Sharjah, Sultan Ben Muhammad al-Qasimi. This allegorical play critiques the hypocrisy of contemporary Arab politics.

Many of the other contributions deal directly or allegorically with corruption and the state of affairs in the Arab world, for example: Yusuf al'Ani's "Where the Power Lies," Tawfiq al-Hakim's "War and Peace," Walid Ikhlasi's "Pleasure Club 21," and Riad Ismat's "Was Dinner Good, Dear Sister?" In addition to Bakri, other Palestinian contributions capture the tragedy of the Palestinian situation, often with humor, including Fateh Azzam's "Baggage" and his collaborative "Ansar." Censorship is taken on by 'Ali Salim in "The Coffee Bar." Mamdouh 'Udwan's two plays, "The Mask" and "Reflections of a Garbage Collector," are scathing critiques of social customs and norms in contemporary Arab society, as is Tawfiq alHakim's "Boss Kanduz's Apartment Building." Perhaps the most incisive plays here are the final three in the collection - Sa'dallah Wannous' "The Glass Café" and "The King's Elephant" and Sa'd al-Din Wahba's "The Height of Wisdom." The remaining five plays are Mahmoud Diyab's "Men Have Heads," Ahmed Ibrahim al-Fagih's "The Singing of the Stars," Alfred Farag's “The Person," Jamal Abu Hamdan's “Actress J's Burial Night," and Raymond Jbara's "The Traveler." 
The anthology is organized alphabetically by the author's last name (as spelled in English). This prevents the problem of categorizing such a broad group of plays that are of different subgenres, periods, styles, and that treat different themes, topics, and issues. On the one hand, this allows them to "speak for themselves" as literary works, rather than being forced into general categories or typologies. On the other hand, as translated works from a literary tradition that is little studied or understood in English, a disassociation from their literary and other contexts is pointed up again by this organizational strategy.

This paperback volume is attractively presented by Interlink Books and relatively inexpensive for such an extensive work, making it practical for teaching purposes. Some errors of translation and transliteration, however, detract from its overall effectiveness. For example, in the glossary, ishlah meaning "take off your clothes" is translated as "if God is willing." Presumably, this word is confused with inshallah. Walid Ikhlasi's first name is transliterated incorrectly as "Waalid" in the table of contents. Also in the table of contents an unusual spelling of Sa'Dallah Wannous (using a capitalized "D") follows the more conventionally spelled, Sa'd al-Din Wahba. This choice of orthography might have been explained for the benefit of students learning Arabic, and spellings of names also maintained consistently throughout the volume (the capitalized " $D$ " disappears where the actual plays are included and recurs in the authors' biographies). This is regrettable in such an anthology, which will be used as a reference work and for teaching, because it will confuse those unfamiliar with Arabic - students and teachers alike.

Like all translation projects from Arabic to English, Short Arabic Plays is an important contribution to the field and a valuable resource for those interested in teaching or studying Arabic literature in translation. Moreover, it should prove useful to those teaching more general literature courses such as drama or otherwise, who would like to include works translated from Arabic. Since no individual piece is longer than 40 pages and some are under 20 pages, they can be used in many different ways. Particularly because these short plays often express poignant and tragic situations using humor, they show a side of Arabic literature and culture often neglected in the English-speaking world. 